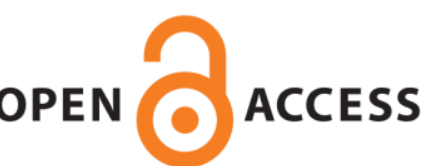

UWS Academic Portal

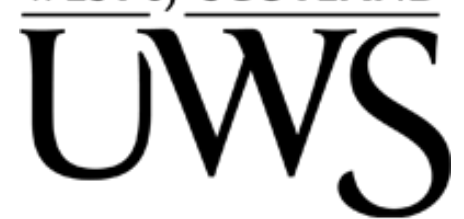

\title{
A systematic review of evidence relating to clinical supervision for nurses, midwives and allied health professionals
}

Pollock, Alex ; Campbell, Pauline; Deery, Ruth; Fleming, Mick; Rankin, Jeanie; Sloan, Graham; Cheyne, Helen

Published in:

Journal of Advanced Nursing

DOI:

$10.1111 /$ jan. 13253

E-pub ahead of print: 08/02/2017

Document Version

Peer reviewed version

Link to publication on the UWS Academic Portal

Citation for published version (APA):

Pollock, A., Campbell, P., Deery, R., Fleming, M., Rankin, J., Sloan, G., \& Cheyne, H. (2017). A systematic review of evidence relating to clinical supervision for nurses, midwives and allied health professionals. Journal of Advanced Nursing. https://doi.org/10.1111/jan.13253

\section{General rights}

Copyright and moral rights for the publications made accessible in the UWS Academic Portal are retained by the authors and/or other copyright owners and it is a condition of accessing publications that users recognise and abide by the legal requirements associated with these rights.

Take down policy

If you believe that this document breaches copyright please contact pure@uws.ac.uk providing details, and we will remove access to the work immediately and investigate your claim. 
DR ALEX POLLOCK (Orcid ID : 0000-0003-4941-7985)

Received Date : 18-Feb-2016

Revised Date : 14-Dec-2016

Accepted Date : 15-Dec-2016

Article type : Review

\section{Full title}

A systematic review of evidence relating to clinical supervision for nurses, midwives and allied health professionals.

\section{Running head}

Clinical supervision for NMAHPs: a systematic review

\section{Author details}

Alex POLLOCK, PhD BSc(Hons), Senior Research Fellow, Nursing Midwifery and Allied Health Professions Research Unit, Glasgow Caledonian University, Glasgow, UK.

Alex.Pollock@gcu.ac.uk

Pauline CAMPBELL, PhD BSc(Hons), Research Fellow, Nursing Midwifery and Allied Health

Professions Research Unit, Glasgow Caledonian University, Glasgow, UK.

Ruth DEERY, PhD ADM RM, Professor of Maternal Health, Institute of Healthcare Policy and Practice, University of the West of Scotland, UK.

Mick FLEMING, PhD MA RMN, Associate Professor, The School of Nursing, Midwifery and Social Care, Napier University, Edinburgh, UK.

Jean RANKIN, PhD RN RM, Professor, Supervisor of Midwives, Health, Nursing and Midwifery, University of the West of Scotland, UK.

Graham SLOAN, PhD RMN RGN, Consultant Nurse in Psychological Therapies, Psychological Services, NHS Ayrshire and Arran, Ayr, UK.

Helen CHEYNE, PhD RM RGN, Royal College of Midwives (Scotland) Professor of Midwifery, Nursing Midwifery and Allied Health Professions Research Unit, University of Stirling, Stirling, UK.

\section{Conflict of interest statement}

No conflict of interest has been declared by the authors (Alex Pollock, Pauline Campbell, Ruth Deery, Mick Fleming, Jean Rankin, Graham Sloan and Helen Cheyne).

This article has been accepted for publication and undergone full peer review but has not been through the copyediting, typesetting, pagination and proofreading process, which may lead to differences between this version and the Version of Record. Please cite this article as doi: $10.1111 /$ jan. 13253

This article is protected by copyright. All rights reserved. 


\section{Funding statement}

This work was commissioned and supported by the Scottish Government's Chief Nursing Officer's Directorate. The Nursing Midwifery and Allied Health Professions (NMAHP) Research Unit is supported by the Scottish Government Health Directorate's Chief Scientist Office. The work presented here represents the view of the authors and not necessarily those of the funding bodies.

\section{Author Contributions}

All authors have agreed on the final version and meet at least one of the following criteria (recommended by the ICMJE*):

1) substantial contributions to conception and design, acquisition of data, or analysis and interpretation of data;

2) drafting the article or revising it critically for important intellectual content.

* http://www.icmje.org/recommendations/

\section{ABSTRACT}

\section{Aim}

To systematically review evidence relating to clinical supervision for nurses, midwives and allied health professionals.

\section{Background}

Since 1902 statutory supervision has been a requirement for UK midwives, but this is due to change. Evidence relating to clinical supervision for nurses and allied health professions could inform a new model of clinical supervision for midwives.

\section{Design}

A systematic review with a contingent design, comprising a broad map of research relating to clinical supervision and two focussed syntheses answering specific review questions.

This article is protected by copyright. All rights reserved. 


\section{Data Sources}

Electronic databases were searched from 2005 - September 2015, limited to English-language peer-reviewed publications.

\section{Review Methods}

Systematic reviews evaluating the effectiveness of clinical supervision were included in Synthesis 1 . Primary research studies including a description of a clinical supervision intervention were included in Synthesis 2. Quality of reviews were judged using a risk of bias tool and review results summarised in tables. Data describing the key components of clinical supervision interventions were extracted from studies included in Synthesis 2, categorised using a reporting framework and a narrative account provided.

\section{Results}

Ten reviews were included in Synthesis 1; these demonstrated an absence of convincing empirical evidence and lack of agreement over the nature of clinical supervision. Nineteen primary studies were included in Synthesis 2; these highlighted a lack of consistency and large variations between delivered interventions.

\section{Conclusion}

Despite insufficient evidence to directly inform the selection and implementation of a framework, the limited available evidence can inform the design of a new model of clinical supervision for UK-based midwives.

This article is protected by copyright. All rights reserved. 


\section{KEY WORDS}

clinical supervision, midwives, nurses, allied health professionals, literature review, systematic review

\section{SUMMARY STATEMENT}

\section{Why is this research or review needed?}

- UK midwives currently receive statutory supervision but changes will soon separate its investigatory and developmental functions. The Nursing and Midwifery Council (NMC) will be responsible for regulation, leaving the opportunity to develop a nonregulatory framework for supervision which may be more effective in meeting the needs of practicing midwives.

- Existing models of clinical supervision currently used for nurses or allied health professionals may inform a framework of non-regulatory supervision for midwives.

- There is a lack of consensus over the nature of clinical supervision and how it can be optimally facilitated.

\section{What are the key findings?}

- An overview of reviews which explore effectiveness of clinical supervision demonstrates consensus that there is no convincing evidence of effectiveness and a lack of agreement over the nature of clinical supervision.

- A synthesis of descriptions of clinical supervision in primary research studies demonstrates that there is lack of consistency and large variations in what is delivered as supervision.

This article is protected by copyright. All rights reserved. 
- There is insufficient evidence to directly inform the selection of a specific model, or way of delivering clinical supervision, to promote optimal outcomes for health practitioners and their clients.

\section{How should the findings be used to influence policy/practice/research/education?}

- These findings could be used to inform the development and implementation of a non-regulatory framework for clinical supervision in midwifery.

- Despite insufficient evidence to enable direct selection of a new framework from existing models, available information about intervention components could be used to inform the design of a new model of clinical supervision for UK midwives which should then be rigorously tested.

- Further systematic exploration of research evidence exploring perceived barriers and facilitators to clinical supervision should be carried out to assist decisions relating to future supervision of midwives in the UK.

\section{INTRODUCTION}

Clinical supervision is widely considered to be an integral part of good professional practice for healthcare practitioners (Bowers and Bottiglien 2007, Brunero and Lamont 2012, Buus et al. 2013, Gonge and Buus 2015, NHS 2013). While there is no universally accepted definition of the term clinical supervision, there is broad agreement over its purpose and objectives. For the purposes of this paper, clinical supervision is considered to be the facilitation of support and learning for healthcare practitioners enabling safe, competent practice and the provision of support to individual professionals who may be working in stressful situations. This reflects definitions from established texts: 
a formal process of professional support and learning which enables individual practitioners to develop knowledge and competence, assume responsibility for their own practice and enhance consumer protection and safety in complex situations (DoH 1993)

clinical supervision provides a route to developing and maintaining emotionally healthier individuals in an emotionally healthier workforce culture. Effective systems of clinical supervision can bring benefits not only to practitioners but also to the organisation and its clients (Bond and Holland 1998).

Internationally there are many frameworks, policies and procedures relating to the concept of clinical supervision, placing responsibility on individual professionals, managers, organisations or health care systems. Reported impacts of clinical supervision comprise benefits at all these different levels, although evidence relating to improved quality of care provided by professionals to individual clients or patients is rare (Bradshaw et al. 2007) and studies have been unable to demonstrate direct and signficant benefits to patients (Watkins 2011; White \& Winstanley 2010). Yet there is widespread consensus over the merits of clinical supervision, despite a lack of clarity over what clinical supervision is and little agreement about what constitutes a 'good' model of clinical supervision (Chilvers and Ramsey 2009, Evans and Marcroft 2015).

In this paper, evidence relating to the effectiveness of clinical supervision interventions is systematically synthesised and descriptions of clinical supervision interventions are derived from primary research evidence.

This article is protected by copyright. All rights reserved. 


\section{Background}

Uniquely, in the UK there is a legal requirement for all midwives to receive regular supervision, but no similar statutory requirement for nurses or allied health professions.

Participation in statutory supervision (i.e. supervision for which there is a legal requirement) has been an essential requirement for midwives in the UK since 1902 to maintain their registration to practice. Statutory supervision purports to provide a mechanism for both regulation of practice (including registration of midwives and investigation in cases of suggested mal-practice) and for support and guidance (including a review of the midwife's practice and an assessment of educational needs). However it has been argued by some that there is a blurring of boundaries in the statutory supervision model and that regulation and support for a midwife cannot exist in the same model (Deery and Corby 1996, Stapleton et al. 1998).

The stated purpose of statutory supervision of midwives is to "protect women and babies by actively promoting a safe standard of midwifery practice' (NHS 2015). Recently, following several enquiries into adverse events, a report from The King's Fund (an independent charity working to improve health and health care in England, which aims to shape policy and practice through research and analysis: http://www.kingsfund.org.uk/) recommended the separation of the processes of supervision and regulation for midwives (Baird et al. 2015) with relevant changes to the law anticipated to be in place by early 2017 (NMC 2015).

The removal of the statutory requirement for supervision of UK midwives represents a significant change for the profession. The UK's Nursing and Midwifery Council will continue to have responsibility for the regulatory aspects of supervision, but not aspects relating to professional and personal support (i.e. not clinical supervision). The current statutory supervision model has traditionally been considered to be essential for the 
protection of the public (i.e. mothers and babies) and its removal implies a threat to public safety. There is therefore a need to adopt a suitable alternative to ensure safety and optimal outcomes for mothers and babies. Consequently the four Chief Nursing Officers in the UK are now seeking to implement a model of clinical supervision (NMC 2015) and the Scottish Government brought together lead midwives and researchers to begin exploration of an alternative model or framework.

However, there are significant challenges to the identification, development and implementation of a robust model of clinical supervision. There is a lack of consensus over the nature of clinical supervision and its facilitation. This creates barriers to the development and implementation of an alternative model of supervision which is designed to meet the professional support and developmental needs of midwives and to have a positive impact on clinical outcomes for women, babies, midwives and maternity services. Non-regulatory models of clinical supervision currently used for nurses and allied health professionals (AHPs) and by midwives outwith the UK, may potentially inform the development of a replacement to statutory supervision and evidence relating to these need to be considered to determine the optimal framework for clinical supervision for midwives in the UK.

\title{
THE REVIEW
}

\begin{abstract}
Aim
The aim was to inform the identification, development and implementation of a framework for clinical supervision in midwifery by exploring evidence relating to clinical supervision for nurses, midwives and AHPs. Identified evidence was synthesised to answer the following research questions:
\end{abstract}

This article is protected by copyright. All rights reserved. 
1. What is the evidence of effectiveness of clinical supervision interventions for nurses, midwives or AHPs?

2. What are the key components of clinical supervision interventions delivered in primary research studies to nurses, midwives and AHPs?

The protocol for this review has been published in the PROSPERO database (Pollock et al. 2015).

\section{Design}

A systematic review using a contingent design was carried out. Contingent designs comprise a cycle of research syntheses, conducted to answer defined research questions and assimilate evidence according to its relevance to a research question, rather than grouping studies according to whether they have a qualitative or quantitative research design (Sandelowski et al. 2006). The process of starting with a broad review question or aim can enable subsequent efficient syntheses focussed on narrower review questions (Gough et al. 2012). The planned contingent design therefore, comprised two stages: (1) mapping the evidence; and (2) synthesising evidence relevant to the two focussed research questions. This is illustrated in Figure 1.

The framework developed by Arksey and O’Malley (2005) provided a structured approach to both stages of the planned systematic review. This framework comprises 5 stages: clarifying and linking the purpose and research question (stage 1); balancing feasibility with breadth and comprehensiveness of the mapping process (stage 2); using an iterative team approach to selecting studies (stage three) and extracting data (stage four); incorporating a numerical summary and qualitative thematic analysis, reporting results and considering the implications 
of study findings to policy, practice, or research (stage five) (Arksey and O'Malley 2005, Levac et al. 2010). To ensure adherence to the 'iterative team approach' the review authors, who comprised experts in clinical supervision, midwifery and research methods, held regular team meetings throughout the review process. This iterative approach ensured that feasibility and timely completion of this review could be balanced with breadth and comprehensiveness.

\section{Search methods}

The electronic databases searched were: MEDLINE, CINAHL, EMBASE, AMED (Allied and Complementary Medicine Database), CDSR (Cochrane Database of Systematic Reviews), DARE (Database of Abstracts of Reviews of Effectiveness), CENTRAL (Cochrane Central Register of Controlled Trials), HTA (Health Technology Assessment Database), from 2005 until September 2015, limited to English language papers in peerreviewed publications. Comprehensive search strategies were developed and adapted for use across databases, combining MESH and free text terms for keywords relating to profession (e.g. 'nurse', 'midwife', 'allied health professional') and supervision (e.g. 'clinical supervision' OR 'professional supervision') (see Table S1 for sample search string for CINAHL database). Boolean operators were used to maximise the penetration of terms searched and appropriate 'wild cards' used to account for plurals, variations in databases and spelling.

This article is protected by copyright. All rights reserved. 


\section{Search outcome}

Selection criteria for inclusion in the broad map of research evidence were purposefully wide.

To be eligible for inclusion studies had to be specifically focussed on clinical supervision, according to the pre-defined working definition (see Introduction). To ensure that included clinical supervision interventions were relevant to the UK, only studies based in Europe, North America or Australasia were eligible for inclusion. Any primary or secondary research studies, regardless of design, were eligible for inclusion, but letters, commentaries, expert opinion and non-peer reviewed studies were excluded.

Studies were excluded if they were exclusively focused on the supervisee only (for example, studies focussing only on resilience building), the supervisor role (for example, studies focussed specifically on processes or actions of the supervision), or education (that is, clinical supervision provided to those completing educational courses or programmes).

An audit trail of the search outcome was maintained, with details of included and excluded studies summarised in tables.

\section{Quality appraisal}

The quality of reviews included in synthesis 1 were assessed using the ROBIS tool (Whiting et al. 2016) and each review rated as being at low, high or unclear risk of bias, based on the responses to the ROBIS questions. The quality of primary research studies included in synthesis 2 were not systematically appraised, as this was not contingent with the aim of this synthesis, which was focused on providing a description of interventions (rather than synthesising or interpreting outcome data), however a judgement of the comprehensiveness 
of the description of the intervention was applied using a pre-planned 'traffic-light' system. The following definitions were used for this categorisation:

- 'Green' - comprehensive description of clinical supervision intervention, with few missing data. Details ought to be sufficient to facilitate replication.

- 'Amber' - Details of some areas of the clinical supervision intervention well reported, but absent for some areas. Details would not be sufficient to facilitate replication, but could be integrated into an intervention with similar characteristics.

- 'Red' - Few details provided and/or inadequate description of the clinical supervision intervention. Details would not be sufficient to facilitate replication of the intervention.

Judgment of comprehensiveness of reporting was done by one researcher and checked by a second researcher.

\section{Methods of selection of studies}

One member of the review team ran the search strategy and excluded any obviously irrelevant titles. Two review authors independently reviewed the abstracts of all remaining records, applying selection criteria to identify eligible studies. Full papers were obtained for all studies considered potentially relevant by at least one reviewer and were independently assessed by two reviewers. Any disagreements between reviewers were resolved through discussion. In accordance with the Arksey and O’Malley (2005) framework, discussion meetings were held to discuss the process of study selection following completion of abstract review, but prior to full paper review, to provide opportunities for discussion and review of 
the inclusion criteria (Arksey and O'Malley 2005). Any agreed modifications to inclusion criteria were fully documented, with reasons provided, to ensure transparency in this process.

Selection of studies for inclusion in synthesis 1: For inclusion in synthesis 1 studies had to be specifically designed to evaluate the effectiveness of the clinical supervision intervention. Outcomes of interest were pre-stated as (but not limited to): measures of cost, numbers of complaints, number of staff sickness days, measure of staff retention and scales to assess perceived acceptability and usefulness. Selection of studies for inclusion in synthesis 1 was carried out through discussion between review authors.

Selection of studies for inclusion in synthesis 2: For synthesis 2, which aimed to synthesise descriptions of clinical supervision interventions, the comprehensiveness of the description of the clinical supervision intervention was judged using the previously described 'traffic light' system. Only studies judged to be 'green' or 'amber' were taken forward into synthesis 2.

\section{Data extraction}

Synthesis 1: Following consensus to focus on relevant reviews, recommended methods for overviews of reviews (or 'umbrella reviews') were adopted. These included ensuring that methods were in line with well-recognised high quality standards for systematic reviews of primary studies (Hartling et al. 2012) and including the essential elements for overviews of reviews including non-quantitative data (Aromataris et al. 2015). The characteristics of the 10 included reviews were systematically extracted, including aims, inclusion criteria, date of search, outcomes assessed, details of included studies, data synthesised, any effectiveness 
data and review conclusion. Data were extracted by one of the review authors, using a data collection form specifically designed for this study.

Synthesis 2: The characteristics of the 19 included studies were systematically extracted, including country of study, study aims, study design and description of the clinical supervision. Data were extracted by one review author, using a data collection form specifically designed for this study.

\section{Synthesis}

Synthesis 1: Extracted data and ROBIS assessments for each review were combined in summary tables. Had the included reviews presented meta-analyses exploring the effectiveness of clinical supervision on any of our pre-stated outcomes of interest, we planned to summarise these pooled data in tables using recommended methods (Hartling et al. 2012, Smith et al. 2011).

Synthesis 2: Descriptions of key components of the clinical supervision intervention were systematically tabulated for each study using items from the TIDieR checklist (Hoffmann et al. 2014), to categorise descriptions under the following headings:

i) BRIEF NAME of model of clinical supervision and WHY it was selected.

ii) WHAT materials and procedures were used?

iii) WHO provided clinical supervision?

iv) HOW was clinical supervision provided?

This article is protected by copyright. All rights reserved. 
v) WHERE was clinical supervision provided?

vi) WHEN and HOW MUCH clinical supervision was provided?

Information on tailoring, modifications and how well the clinical supervision was implemented was considered and relevant descriptions incorporated in the above categories.

Differences and similarities between studies in each of these categories were explored.

\section{RESULTS}

\section{Results of search}

The results of the search are detailed in Figure 2. Eighty-six papers, which reported 47 primary studies (60 papers) and 26 reviews were included in the broad map of evidence.

\section{Synthesis 1}

Iterative discussion in accordance with the planned design (Arksey and O'Malley 2005) led to consensus that it was pragmatic and efficient to first consider whether the 26 reviews included in the broad map answered the research question in proposed synthesis 1 . Exploration of these reviews led to exclusion of 16 reviews (see Table S2 for reasons for exclusion and references for excluded reviews), leaving 10 reviews to be included in Synthesis 1 (Brunero 2008, Butterworth et al. 2008, Buus and Gonge 2009, Dawson et al. 2013, Dilworth et al. 2013, Ducat and Kumar 2015, Fitzpatrick et al. 2012, Francke and de Graaff 2012, Kleiser and Cox 2008, Pearce et al. 2013). Characteristics of these reviews are detailed in Table S3. Only 5 of these 10 included were judged to be a low risk of bias (using the ROBIS tool) and relevant to our review question (Buus and Gonge 2009, Dawson et al. 
2013, Dilworth et al. 2013, Ducat and Kumar 2015, Francke and de Graaff 2012). Four of these included qualitative primary research studies in addition to quantitative studies (Buus and Gonge 2009, Dawson et al. 2013, Dilworth et al. 2013, Ducat and Kumar 2015, Francke and de Graaff 2012), while one included quantitative studies only (Francke and de Graaff 2012). None of the reviews pooled any data in meta-analyses; one review presented quantitative results data from individual studies (Francke and de Graaff 2012). All 5 reviews provided narrative descriptions of the results of the included primary studies.

Systematic exploration of the evidence from all reviews of clinical supervision (including those judged to be at high risk of bias) demonstrates clear consensus that there is lack of agreement over what clinical supervision is or how it should be performed and that there is no convincing empirical evidence to support clinical supervision for nurses, midwives and AHPs (NMAHPs). The reviews were also in general agreement that while there is some evidence of limited quality, which does suggest benefits associated with clinical supervision, this is conflicting and the evidence is low quality and poorly described.

\section{Synthesis 2}

The 47 primary research studies were all considered to potentially include relevant descriptions of clinical supervision interventions. Application of the 'traffic light' system to rate the comprehensiveness of the description of the clinical supervision intervention rated 3/47 as 'green', 16/47 as 'amber' and 28/47 as 'red'. Table S4 summarises the study design, judgement of quality / comprehensiveness of description of clinical supervision and Table S5 describes the characteristics and lists citations for the 48 primary studies.

This article is protected by copyright. All rights reserved. 
Thus 19 primary studies were judged to contain some details relating to the clinical supervision intervention. These included 4 randomised controlled trials (Bambling et al. 2006, Gonge and Buus 2015, Heaven et al. 2006, White and Winstanley 2010), one cohort study (Livni et al. 2012), 3 mixed methods studies (Dawber 2013, O'Connell et al. 2013, Turner and Hill 2011), 2 qualitative studies ((Brink et al. 2012, Cross et al. 2010), 5 survey/questionnaire-based studies (Bailey et al. 2014, Brunero and Lamont 2012, Buus et al. 2013, Evans and Marcroft 2015, Girling et al. 2009), 3 case studies or reports (Bowers and Bottiglien 2007, Chilvers and Ramsey 2009, Cross et al. 2012) and one action research study (Bergdahl et al. 2011). The numbers of people participating in the studies was generally low (ranging from 2-87 supervisees) and were often poorly reported, with many studies describing the number of groups receiving supervision or the number of supervisors rather than number of supervisees.

\section{Narrative description of key components}

\section{i) BRIEF NAME of model of clinical supervision and WHY it was selected.}

There were several different named models of supervision cited with several studies referring to more than one named model. The most frequently cited model of supervision was Proctor's model (Proctor 1987, 2000), with 8/19 studies specifically referring to Proctor's Model (Bowers and Bottiglien 2007, Brunero and Lamont 2012, Cross et al. 2010, Dawber 2013, Gonge and Buus 2015, Evans and Marcroft 2015, Turner and Hill 2011, White and Winstanley 2010). Models of reflective practice were cited by 3 studies (Chilvers and Ramsey 2009, Dawber 2013, White and Winstanley 2010), while other studies described 'Working Alliance' (Bambling et al. 2006), 'Collegial group supervision' (Brink et al. 2012), 'Supervisory Alliance' (Livni et al. 2012), models of 'Hawkins and Shohet' (Buus et al. 
2013) and 'Bandura's social cognitive learning' model (Heaven et al. 2006). Only 4/19 studies (Bergdahl et al. 2011, Cross et al. 2012, Girling et al. 2009, O'Connell et al. 2013) did not state a named model of clinical supervision or cite a supporting reference when describing the intervention. However, in the papers where specifically named models were cited, it was generally unclear how these models had an impact on the practical application of clinical supervision and why this particular model had been selected.

\section{ii) WHAT materials and procedures were used?}

Few studies provided a comprehensive description of the content of the sessions and how these were structured. Two of the studies specifically referred to the establishment of 'ground rules' at the start of the clinical supervision process (Bowers and Bottiglien 2007, Turner and Hill 2011). Some studies either implicitly or explicitly described a process where a 'problem' or 'issue' was raised and then explored by the supervisee (Brunero and Lamont 2012, Cross et al. 2010, Cross et al. 2012, O'Connell et al. 2013). In general the descriptions provided in the study lacked clarity around the content and structure of the sessions.

In the majority of the studies (9/19) participation in clinical supervision was voluntary. In one study it was stated that participation was not mandatory, but that staff were 'strongly advised to attend' (Chilvers and Ramsey 2009), while in another it was mandatory for participants in one setting (ward) and voluntary in another (Buus et al. 2013). In two studies participation required consent for ethical reasons associated with the study design (Heaven et al. 2006, White and Winstanley 2010) and information was unclear or not stated in three studies.

This article is protected by copyright. All rights reserved. 
There was very little information provided in the studies in relation to whether (or how) clinical supervision sessions were documented. Two studies stated that records or notes were kept by the supervisors (Cross et al. 2010, Livni et al. 2012), one mentioned minutes of meetings (Bowers and Bottiglien 2007) and two used standard forms to record the session (Chilvers and Ramsey 2009, Turner and Hill 2011).

\section{iii) WHO PROVIDED clinical supervision?}

Clinical supervision was facilitated by a range of different people, with very varied levels of experience in clinical supervision. Three main groups of people who provided or facilitated supervision were identified; these included (1) clinical supervision facilitator who had completed specialist training (Cross et al. 2010, Cross et al. 2012, Dawber 2013, Girling et al. 2009, O'Connell et al. 2013), (2) clinical NMAHPs who had attended some training (Bambling et al. 2006, Chilvers and Ramsey 2009, Evans and Marcroft 2015, Livni et al. 2012, White and Winstanley 2010) and (3) members of a group where the lead person, or facilitator, rotated between members (Bailey et al. 2014, Heaven et al. 2006, Bowers and Bottiglien 2007). Other people involved in facilitating clinical supervision were researchers (Buus et al. 2013, Gonge and Buus 2015) and line managers (Turner and Hill 2011). In one study clinical supervision was delivered jointly by two co-facilitators (Brunero and Lamont 2012).

The training provided to clinical NMAHPs comprised a 2-day university course tailored to the supervisor's needs (Chilvers and Ramsey 2009) and a 4-day 'residential, intensive, experiential' course combining practical exercises with theory-based seminars (White and Winstanley 2010). Another study provided one training session and a manual, but all supervisors in this study had to have previously had at least 2 years' experience of providing 
clinical supervision (Bambling et al. 2006). Three studies provided supervisors with a written manual, or handbook, detailing the role and functions of clinical supervision (Brunero and Lamont 2012, Buus et al. 2013, Gonge and Buus 2015).

\section{iv) HOW was clinical supervision provided?}

All clinical supervision interventions were delivered face-to-face. The majority of studies focussed on group supervision (12/19) (Bailey et al. 2014, Bergdahl et al. 2011, Bowers and Bottiglien 2007, Brink et al. 2012, Brunero and Lamont 2012, Buus et al. 2013, Chilvers and Ramsey 2009, Cross et al. 2010, Dawber 2013, Gonge and Buus 2015, O'Connell et al. 2013, White and Winstanley 2010). This was generally led by a facilitator, but occasionally is peerled (Cross et al. 2010). Five studies delivered individual (one-to-one) supervision (Bambling et al. 2006, Cross et al. 2012, Girling et al. 2009, Heaven et al. 2006, Turner and Hill 2011), while 2 delivered a mixture of either group or individual (Evans and Marcroft 2015, Livni et al. 2012). Evans and Marcroft (2015) specifically planned to enable a range of different modes of delivery, stating that 'A menu of 6 options was provided to enable supervision to be adaptable and tailored to individual staff \& service needs' (Evans and Marcroft 2015). In Livni et al. 2012 supervisors and supervisees were randomly allocated to either individual or group supervision conditions (Livni et al. 2012).

\section{v) WHERE was clinical supervision provided?}

The included studies were mainly carried out in Australia (8 studies: (Bailey et al. 2014, Bambling et al. 2006, Brunero and Lamont 2012, Cross et al. 2010, Cross et al. 2012, Dawber 2013, O'Connell et al. 2013, White and Winstanley 2010) and the United Kingdom (7 studies: 
(Bowers and Bottiglien 2007, Chilvers and Ramsey 2009, Evans and Marcroft 2015, Girling et al. 2009, Heaven et al. 2006, Livni et al. 2012, Turner and Hill 2011) with 2 studies also carried out in each of Sweden (Bergdahl et al. 2011, Brink et al. 2012) and Denmark (Buus et al. 2013, Gonge and Buus 2015).

Clinical supervision was provided in a wide variety of different settings including hospital, community and emergency care settings. Six of the studies explored clinical supervision either in a mental health care setting (Bambling et al. 2006, Buus et al. 2013, Gonge and Buus 2015, White and Winstanley 2010) or to supervisees who were involved in the delivery of counselling services (Bailey et al. 2014, Livni et al. 2012). Clinical supervision was often provided to nurses (including registered nurses and midwives, health-care assistants, nurse managers) working in a range of settings including community / home-based services (Bergdahl et al. 2011, Bowers and Bottiglien 2007, Cross et al. 2012, Heaven et al. 2006), general or mixed hospital settings (Brunero and Lamont 2012, Dawber 2013, O'Connell et al. 2013), or specialist care settings (Chilvers and Ramsey 2009, Cross et al. 2010). Clinical supervision was also provided to clinical staff (including nurses and AHPs) in specific settings or locations (Evans and Marcroft 2015, Girling et al. 2009) and to ambulance nurses and technicians (Brink et al. 2012).

\section{vi) WHEN and HOW MUCH clinical supervision was provided?}

There was little evidence available regarding the frequency of participation in clinical supervision. The frequency of clinical supervision can be measured as the number of sessions conducted or, more specifically, as the number of sessions an individual nurse has attended (Gonge and Buus 2015). The frequency and duration of clinical supervision delivered in group or one to one sessions is summarized in Table 1. Group sessions were delivered 
between once a week and every 8 weeks and varied between 45 minutes and 2 hours in length. One to one sessions varied from a 1 hour session once a fortnight, to a 1 hour session once every 3 months. One study reported a total of 12 hours supervision delivered as four $1 / 2$ day sessions over a four week period (Heaven et al. 2006); in this study clinical supervision was delivered specifically with the aim of supporting transfer of communication skills training into clinical practice, potentially accounting for the greater duration of delivery. Another study reported clinical supervision which occurred after each client (Bambling et al. 2006), but this was delivered in the context of a randomised controlled trial, with the aim of supporting adherence to a specific treatment protocol.

\section{DISCUSSION}

This systematic review has mapped research evidence relating to clinical supervision and synthesised evidence to address two clearly focussed research questions. In general the evidence relating to clinical supervision is of poor quality, confounded by absence of definitions and descriptions of clinical supervision. Despite the widespread acceptance that clinical supervision is beneficial to individuals, clients and organisations, there remains no convincing empirical evidence to support clinical supervision for nurses, midwives or allied health professionals. Exploration of the few available descriptions of clinical supervision in the primary research evidence highlights inconsistencies and large variations between facilitated interventions. There is insufficient evidence to inform the selection of a specific model, or way of facilitating clinical supervision, to promote optimal outcomes for health practitioners and their clients.

This article is protected by copyright. All rights reserved. 


\section{Implications for midwifery and clinical supervision in the UK}

The midwifery profession is now in a unique position to be able to devise a model of clinical supervision that meets the needs of midwives in the UK. Although the findings of this review provide insufficient evidence to directly inform the selection of a clinical supervision model for midwives, information about intervention components relating to typology, processes and the role of the facilitator may help inform the design of a model of clinical supervision which can then be rigorously tested. Named models of supervision may inform development, but care must be taken to consider how such models have an impact on the practical application of clinical supervision. As there are a range of ways of delivering clinical supervision and no evidence of superiority of any specific method, incorporating several alternatives into a model may be advantageous in enabling tailoring to different settings and individual practitioners. Specification of the components of a new model and development of a handbook or manual may provide a practical way of ensuring clarity and may be a useful supplement to any training which is provided to those who will facilitate clinical supervision sessions. It will be essential to be clear about whether participation in clinical supervision sessions will be voluntary or mandatory, both as a supervisor or as a supervisee. Development of contracts between supervisors and supervisees, standard methods of record keeping and minimum criteria for attendance of individual midwives may all be important components.

Given that the new model will not have a regulatory function this presents the opportunity for a focus on bringing and reflecting on, issues from work in a safe and supportive, but challenging context. To provide optimal care to mothers and babies, midwives require adequate support and guidance; consequently there is a case that this new model should be predicated on relationship based care, ensuring that midwives do not suffer from the stresses that have become common in midwifery and enabling them to take care of themselves as well 
as mothers and babies. Effective clinical supervision is likely to require continuous learning and development for supervisors and supervisees, who will need to be committed to selfassessing their skills and competencies through reflection and review of their performance. Appropriate training and knowledge development, for both supervisors and supervisees, will arguably be essential to ensuring successful implementation of a new supervision process. To successfully develop and implement a national framework of clinical supervision for UK midwives each individual component of this complex intervention will need to be considered, with consideration of the context where it is to implemented and with collaboration from all relevant stakeholders.

\section{Strengths and limitations of the review}

The lack of consistent terminology relating to clinical supervision led to significant challenges associated with identification of relevant studies, which may have led to failure to identify and include some potentially relevant papers. However the large number of review papers identified and the clear consensus in their reported findings, does increase confidence that there were no key papers missing from this review. The conclusions reached in this systematic review are limited by the poor quality of evidence identified relating to clinical supervision. In synthesis 1 a recognised tool was used to assess the quality of evidence of the included reviews and a strength of this approach was the focus on the reviews which were judged to be at low risk of bias. In contrast, in synthesis 2 no assessment of the quality of the included primary studies was made, as quality was not considered relevant to the research question, which specifically focused on the description of the intervention, rather than on the study design or results. Despite this justification, the absence of quality assessment may have resulted in inclusion of data from studies which had study designs at high risk of bias. 
Throughout this review, strategies were implemented to reduce the introduction of biases, including the use of two independent reviewers at all key stages of the study selection and data extraction and transparent reporting of judgements and decision making. The review authors did make several iterative decisions, potentially introducing bias into the review, but attempts were made to systematically document all iterative decision-making to minimise the limitations associate with this approach.

\section{CONCLUSION}

This systematic review of evidence relating to clinical supervision was undertaken to inform the development and implementation of a framework for clinical supervision in midwifery. While the review highlights the lack of high quality evidence relating to clinical supervision and concludes that this is insufficient to directly inform the selection and implementation of a new framework, the limited available evidence could be used to inform the design of a new model of clinical supervision for UK-based midwives. The absence of empirical evidence relating to the effectiveness of clinical supervision interventions and variations and inconsistencies in descriptions, definitions and what is implemented in clinical practice, provide no clear way forward in the identification of a replacement for statutory supervision for UK-based midwives. Yet clinical supervision is widely delivered and there are a considerable number of peer-reviewed papers where there are reports of the facilitation of clinical supervision for nurses, midwives and AHPs. The available evidence provides a range of options which could be considered during the development of a new model or framework for clinical supervision in midwifery in the UK. To further inform this development and implementation, systematic exploration of additional data, such as evidence relating to the 
perceived barriers and facilitators to effective supervision and reports of current practice for other health professionals, is recommended.

\section{Author Contributions:}

All authors have agreed on the final version and meet at least one of the following criteria (recommended by the ICMJE*):

1) substantial contributions to conception and design, acquisition of data, or analysis and interpretation of data;

2) drafting the article or revising it critically for important intellectual content.

* http://www.icmje.org/recommendations/

\section{REFERENCES}

Arksey, A. \& O'Malley, L. (2005) Scoping studies: towards a methodological framework. International Journal of Social Research Methodology, 8(1), 19-32.

Aromataris, E., Fernandez, R., Godfrey, C.M., Holly, C., Khalil, H. \& Tungpunkom, P. (2015) Summarizing systematic reviews: methodological development, conduct and reporting of an umbrella review approach. Int J Evid Based Healthc, 13(3), 132-40.

Bailey, R., Bell, K., Kalle, W. \& Pawar, M. (2014) Restoring Meaning to Supervision Through a Peer Consultation Group in Rural Australia. Journal of Social Work Practice, 28(4), 479-495.

This article is protected by copyright. All rights reserved. 
Baird, B., Murray, R., Seale, B., Foot, C. \& Perry, C. (2015) Midwifery regulation in the United Kingdom. The King's Fund, London, UK.

Bambling, M., King, R., Raue, P., Schweitzer, R. \& Lambert, W. (2006) Clinical supervision: Its influence on client-rated working alliance and client symptom reduction in the brief treatment of major depression. Psychotherapy Research, 16, 317-331.

Bergdahl, E., Benzein, E., Ternestedt, B.M. \& Andershed, B. (2011) Development of nurses' abilities to reflect on how to create good caring relationships with patients in palliative care: an action research approach. Nursing Inquiry, 18(2), 111-122.

Bond, M. \& Holland, S. (1998) Skills of Clinical Supervision for Nurses, Open University Press, Buckingham.

Bowers, B. \& Bottiglien, T. (2007) The value of a staff nurse forum in meeting the local needs of a district nursing service. Primary Health Care, 17(8), 34-38.

Brink, P., Bäck-Pettersson, S. \& Sernert, N. (2012) Group supervision as a means of developing professional competence within pre-hospital care. International Emergency Nursing, 20(2), 76-82.

Brunero, S. (2008) The effectiveness of clinical supervision in nursing: an evidenced based literature review. Australian Journal of Advanced Nursing, 25(3), 86-94.

Brunero, S. \& Lamont, S. (2012) The process, logistics and challenges of implementing clinical supervision in a generalist tertiary referral hospital. Scand J Caring Sci, 26(1), 18693.

Butterworth, T., Bell, L., Jackson, C. \& Majda, P. (2008) Wicked spell or magic bullet? A review of clinical supervision literature 2001-2007. Nurse Education Today, 28, 264-272. 
Buus, N., Cassedy, P. \& Gonge, H. (2013) Developing a manual for strengthening mental health nurses' clinical supervision. Issues Ment Health Nurs, 34(5), 344-9.

Buus, N. \& Gonge, H. (2009) Empirical studies of clinical supervision in psychiatric nursing: A systematic literature review and methodological critique. Int J Ment Health Nurs, 18(4), 250-64.

Chilvers, R. \& Ramsey, S. (2009) Implementing a clinical supervision programme for nurses in a hospice setting. Int J Palliat Nurs, 15(12), 615-9.

Cross, W., Moore, A. \& Ockerby, S. (2010) Clinical supervision of general nurses in a busy medical ward of a teaching hospital. Contemp Nurse, 35(2), 245-53.

Cross, W.M., Moore, A.G., Sampson, T., Kitch, C. \& Ockerby, C. (2012) Implementing clinical supervision for ICU Outreach Nurses: a case study of their journey. Australian Critical Care 25(4), 263-270.

Dawber, C. (2013) Reflective practice groups for nurses: a consultation liaison psychiatry nursing initiative: part 2--the evaluation. Int J Ment Health Nurs, 22(3), 241-8.

Dawson, M., Phillips, B. \& Leggat, S. (2013) Clinical supervision for allied health professionals: a systematic review. J Allied Health, 42(2), 65-73.

Deery, R. \& Corby, D. (1996) Chapter 14: A Case for Clinical Supervision in Midwifery. In Supervision of Midwives(Kirkham, M. ed. Books for Midwives Press, London.

Dilworth, S., Higgins, I., Parker, V., Kelly, B. \& Turner, J. (2013) Finding a way forward: a literature review on the current debates around clinical supervision. Contemp Nurse, 45(1), 22-32.

This article is protected by copyright. All rights reserved. 
DoH (1993) A Vision for the Future: The Nursing, Midwifery and Health Visiting Contribution to Health and Health Care. (HMSO ed. London.

Ducat, W.H. \& Kumar, S. (2015) A systematic review of professional supervision experiences and effects for allied health practitioners working in non-metropolitan health care settings. J Multidiscip Healthc, 8, 397-407.

Evans, C. \& Marcroft, E. (2015) Clinical supervision in a community setting. Nurs Times, 111(22), 16-8.

Fitzpatrick, S., Smith, M. \& Wilding, C. (2012) Quality allied health clinical supervision policy in Australia: a literature review. Aust Health Rev, 36(4), 461-5.

Francke, A.L. \& de Graaff, F.M. (2012) The effects of group supervision of nurses: a systematic literature review. Int J Nurs Stud, 49(9), 1165-79.

Girling, A., Leese, C. \& Maynard, L. (2009) How clinical supervision can improve hospice care for children. Nursing Management 16(7), 20-23.

Gonge, H. \& Buus, N. (2015) Is it possible to strengthen psychiatric nursing staff's clinical supervision? RCT of a meta-supervision intervention. Journal of Advanced Nursing, 71(4), 909-921.

Gough, D., Thomas, J. \& Oliver, S. (2012) Clarifying differences between review designs and methods. Systematic Reviews, 1, 28.

Hartling, L., Chisholm, A., Thomson, D. \& Dryden, D.M. (2012) A descriptive analysis of overviews of reviews published between 2000 and 2011. PLoS One, 7(11), e49667.

This article is protected by copyright. All rights reserved. 
Heaven, C., Clegg, J. \& Maguire, P. (2006) Transfer of communication skills training from workshop to workplace: the impact of clinical supervision. Patient Educ Couns, 60(3), 31325.

Hoffmann, T.C., Glasziou, P.P., Boutron, I., Milne, R., Perera, R., Moher, D., Altman, D.G., Barbour, V., Macdonald, H., Johnston, M., Lamb, S.E., Dixon-Woods, M., McCulloch, P., Wyatt, J.C., Chan, A.W. \& Michie, S. (2014) Better reporting of interventions: template for intervention description and replication (TIDieR) checklist and guide. BMJ, 348, g1687.

Kleiser, H. \& Cox, D.L. (2008) The Integration of Clinical and Managerial Supervision: a Critical Literature Review. British Journal of Occupational Therapy, 71(1), 2.

Levac, D., Colquhoun, H. \& O'Brien, K.K. (2010) Scoping studies: advancing the methodology. Implement Sci, 5, 69.

Livni, D., Crowe, T.P. \& Gonsalvez, C.J. (2012) Effects of supervision modality and intensity on alliance and outcomes for the supervisee. Rehabil Psychol, 57(2), 178-86.

NHS (2013) NHS Grampian: Clinical supervision (Reflective Learning) Policy \& Guidelines for Nurses, Midwives \& Allied Health Professionals. NHSGCS POL/2013, Scotland.

NHS (2015) NHS England: Supervision of midwives. NHS England.

NMC (2015) Nursing and Midwifery Council. Review of midwifery regulation. An update on midwifery regulation.

O'Connell, B., Ockerby, C.M., Johnson, S., Smenda, H. \& Bucknall, T.K. (2013) Team clinical supervision in acute hospital wards: a feasibility study. West J Nurs Res, 35(3), 33047.

This article is protected by copyright. All rights reserved. 
Pearce, P., Phillips, B., Dawson, M. \& Leggat, S.G. (2013) Content of clinical supervision sessions for nurses and allied health professionals: A systematic review. Clinical Governance, 18(2), 139-154.

Pollock, A., Campbell, P., Deery, R., Fleming, M., Rankin, J., Sloan, G. \& Cheyne, H. (2015) Clinical supervision for NMAHPs: a rapid systematic review of research evidence. PROSPERO:CRD42015026647 Available from http://www.crd.york.ac.uk/PROSPERO/display_record.asp?ID=CRD42015026647

Sandelowski, M., Voils, C.I. \& Barroso, J. (2006) Defining and Designing Mixed Research Synthesis Studies. Res Sch, 13(1), 29.

Smith, V., Devane, D., Begley, C.M. \& Clarke, M. (2011) Methodology in conducting a systematic review of systematic reviews of healthcare interventions. BMC Med Res Methodol, 11(1), 15.

Stapleton , H., Duerden, J. \& Kirkham (1998) Evaluation of the impact of the supervison of midiwves on professional practice and the quality of midiwifery care. Research commissioned by the English National Board, London and UKCC, University of Sheffield.

Turner, J. \& Hill, A. (2011) Implementing clinical supervision (part 2): using proctor's model to structure the implementation of clinical supervision in a ward setting. Mental Health Nursing, 31(4), 14-19.

White, E. \& Winstanley, J. (2010) A randomised controlled trial of clinical supervision: selected findings from a novel Australian attempt to establish the evidence base for casual relationships with quality of care and patient outcomes, as an informed contribution to mental health nursing practice development. Journal of Research in Nursing, 15(2), 151-67. 
Whiting, P., Savovic, J., Higgins, J.P., Caldwell, D.M., Reeves, B.C., Shea, B., Davies, P.,

Kleijnen, J., Churchill, R. \& ROBIS group. (2016) ROBIS: A new tool to assess risk of bias in systematic reviews was developed. J Clin Epidemiol, 69, 225-34.

TABLE 1: WHEN and HOW MUCH clinical supervision

\begin{tabular}{|c|c|c|}
\hline Study & Frequency of clinical supervision & Duration of session \\
\hline \multicolumn{3}{|c|}{ Group clinical supervision } \\
\hline $\begin{array}{l}\text { (Bailey et al. } \\
\text { 2014) }\end{array}$ & $\begin{array}{l}\text { "group would meet one evening per } \\
\text { month" }\end{array}$ & 90 minutes \\
\hline $\begin{array}{l}\text { (Bergdahl et al. } \\
\text { 2011) }\end{array}$ & $\begin{array}{l}13 \text { sessions with approximately } 5 \text { weeks } \\
\text { between the sessions }\end{array}$ & 2 hours \\
\hline $\begin{array}{l}\text { (Bowers and } \\
\text { Bottiglien 2007) }\end{array}$ & Monthly & 2 hours \\
\hline $\begin{array}{l}\text { (Brink et al. } \\
\text { 2012) }\end{array}$ & Not stated & Not stated \\
\hline $\begin{array}{l}\text { (Brunero and } \\
\text { Lamont 2012) }\end{array}$ & $\begin{array}{l}\text { Fortnightly to monthly "dependent on } \\
\text { the clinical area" }\end{array}$ & 1 hour \\
\hline $\begin{array}{l}\text { (Buus et al. } \\
2013 \text {, Gonge } \\
\text { and Buus 2015) }\end{array}$ & $\begin{array}{l}\text { Three sessions: introduction ( } 3 \text { hours) } \\
\text { followed } 6 \text { weeks later by two follow-up } \\
\text { sessions (lasting one hour each) }\end{array}$ & $\begin{array}{l}\text { Varied (manual described an intervention } \\
\text { with three sessions: introductory session } \\
\text { lasting three hours and, at about six weeks } \\
\text { interval, two follow-up sessions lasting one } \\
\text { hour each) }\end{array}$ \\
\hline $\begin{array}{l}\text { (Chilvers and } \\
\text { Ramsey 2009) }\end{array}$ & Every 8 weeks & Six sessions; length of session not stated \\
\hline $\begin{array}{l}\text { (Cross et al. } \\
2010 \text { ) }\end{array}$ & Weekly & 15 sessions, 1 hour length over 6 months \\
\hline (Dawber 2013) & $\begin{array}{l}\text { Model } 1 \text { = alternated between } \\
\text { fortnightly and monthly sessions. Model } \\
2 \text { = between fortnightly and monthly, } \\
\text { based on perceived need. Model } 3=\end{array}$ & $\begin{array}{l}\text { Model } 1=45 \text { minutes. Model } 2=1 \text { hour. } \\
\text { Model } 3=1 \text { hour. }\end{array}$ \\
\hline
\end{tabular}

This article is protected by copyright. All rights reserved. 


\begin{tabular}{|c|c|c|}
\hline & fortnightly. & \\
\hline $\begin{array}{l}\text { (O'Connell et al. } \\
\text { 2013) }\end{array}$ & Weekly & 1 hour \\
\hline $\begin{array}{l}\text { (White and } \\
\text { Winstanley } \\
\text { 2010) }\end{array}$ & Monthly & $45-60$ minutes \\
\hline \multicolumn{3}{|c|}{ One-to-one clinical supervision } \\
\hline $\begin{array}{l}\text { (Bambling et al. } \\
2006)\end{array}$ & $\begin{array}{l}\text { After each client (treated within a } \\
\text { randomised controlled trial) }\end{array}$ & Not stated \\
\hline $\begin{array}{l}\text { (Cross et al. } \\
2012 \text { ) }\end{array}$ & Fortnightly & 1 hour sessions, delivered over 12 months \\
\hline $\begin{array}{l}\text { (Girling et al. } \\
\text { 2009) }\end{array}$ & Every 3 months & 1 hour \\
\hline $\begin{array}{l}\text { (Heaven et al. } \\
\text { 2006) }\end{array}$ & Four $1 / 2$ day sessions & Total of 12 hours, delivered over 4 weeks \\
\hline $\begin{array}{l}\text { (Turner and Hill } \\
\text { 2011) }\end{array}$ & Usually monthly & Not stated \\
\hline
\end{tabular}

This article is protected by copyright. All rights reserved. 


\section{FIGURE 1: Systematic map of planned review design}

\begin{tabular}{|c|c|c|}
\hline & \multicolumn{2}{|c|}{$\begin{array}{l}\text { Broad aim: to inform the identification, } \\
\text { development and implementation of a } \\
\text { framework for clinical supervision in } \\
\text { midwifery by exploring evidence relating } \\
\text { to clinical supervision for NMAHPs }\end{array}$} \\
\hline & \multicolumn{2}{|c|}{$\begin{array}{l}\text { Broad map: research evidence relating to } \\
\text { clinical supervision for NMAHPs (focus and } \\
\text { design) }\end{array}$} \\
\hline \multicolumn{2}{|c|}{$\begin{array}{l}\text { Synthesis 1: What is the evidence } \\
\text { of effectiveness of clinical } \\
\text { supervision interventions for } \\
\text { NMAHPs? }\end{array}$} & $\begin{array}{l}\text { Synthesis 2: What } \\
\text { components of clin } \\
\text { interventions deliv } \\
\text { primary research st } \\
\text { NMAHPs? }\end{array}$ \\
\hline
\end{tabular}

NMAHPs - Nurses, midwives and allied health professionals

This article is protected by copyright. All rights reserved. 
FIGURE 2: Results of search and identification and inclusion of studies within 2 syntheses

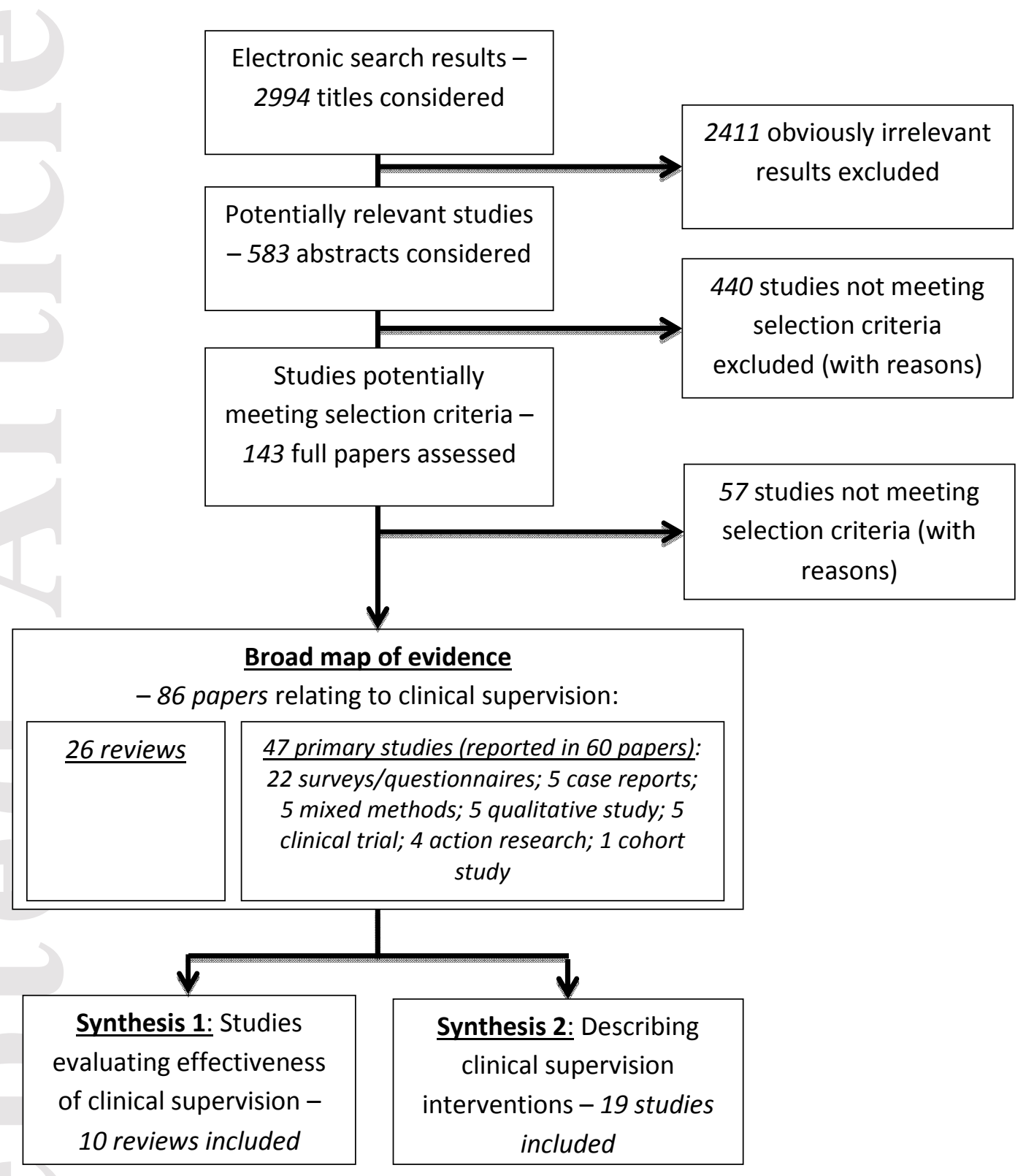

This article is protected by copyright. All rights reserved. 